Vol. 1

No. 1

Jul - Dic 2016

ISSN: $2590-9215$ (En línea)

PP: $50-72$

\title{
Políticas neoliberales y reconfiguraciones urbanas. Victoria, San Fernando, provincia de Buenos Aires, una ciudad entendida desde la teoría*
}

\author{
Neoliberal policies and urban reconfigurations. Victoria, San Fernando, province of \\ Buenos Aires, a city understood from theory
}

\section{Políticas neoliberais e re-configurações urbanas. Victoria, San Fernando, província de Buenos Aires, uma cidade entendida a partir da teoria *}

\author{
Laura Ester Donadío ${ }^{* *}$, Martha Jeannette Torrez-Virviescas ${ }^{* * *}$
}

Forma de citar: Donadío, L. E., y Torrez, J. (2016). Políticas neoliberales y reconfiguraciones urbanas. Victoria, San Fernando, provincia de Buenos Aires, una ciudad entendida desde la teoría. Perspectivas. 1(1). 50-72.

Recibido:

Diciembre 03 de 2015

Aceptado:

Abril 22 de 2016

\section{Resumen:}

El presente artículo pretende explicar desde un acercamiento teórico conceptual las particularidades que existen en Victoria, San Fernando, Buenos Aires, desde su producción urbana. Mediante una serie de trabajos de campo, entrevistas semiestructuradas y observaciones se pudo vislumbrar que en dicha localidad, coexisten tres lógicas de producción de ciudad, la del mercado, el Estado y la necesidad, según las concibe Abramo, P. (2002) características de las ciudades post-desarrollistas latinoamericanas, espacio en el que se generan constantes tensiones que alteran el desarrollo armónico de la vida cotidiana y la interacción de quienes habitan la zona. Por otro lado, se percibe también, que los habitantes naturalizan ese modo de vida, su disposición espacial, la progresiva privatización de áreas públicos y la proliferación de urbanizaciones cerradas. Se cita a continuación una frase que hemos escuchado repetidas veces en entrevistas a los vecinos: "En Victoria nadie le da bolilla a nadie". Al momento de entender Victoria desde la teoría se toma en consideración conceptos como: el de "heterotopía" de Foucault M. (1967) -entendido como la yuxtaposición de espacios que serían incompatibles-, el término "ciudad com-fusa" (Abramo P.,) -en tanto estructura urbana que entrelaza dos modelos tradicionales (la urbe compacta mediterránea y la difusa anglosajona), la noción de "privatopia” de I.Rodriguez Chumillas (2005) y E. Mckenzie (1994) -como la consolidación espacial privada y por último los conceptos: ciudades informativas y duales de R Castells (1995) términos que se desprenden del proceso de globalización, los cuales pueden ser de utilidad para pensar la realidad de Victoria.

Palabras claves: Ciudad com-fusa, heterotopías, interacción, políticas neoliberales, privatopías, reconfiguraciones urbanas, victoria.

\footnotetext{
*El presente trabajo se enmarca en el Proyecto UBACYT del Instituto de Investigación Gino Germani, dependiente de la Facultad de Ciencias Sociales de la Universidad de Buenos Aires: "Investigación sobre los espacios y las formas en que interactúan los distintos sectores socio-urbanos en el área de Victoria, San Fernando, Buenos Aires, entre el período que va desde el año 2011 al 2014”, dirigido por la Arquitecta Celia Guevara y que actualmente se encuentra en desarrollo.

** Licenciada en Sociología. Facultad de Ciencias Sociales, Universidad de Buenos Aires. Laura_donadio@hotmail.com. Teléfono: 50683580222. San José, Costa Rica.

*** Licenciada en Sociología. Facultad de Ciencias Sociales, Universidad de Buenos Aires. Profesora de Metodología de la Investigación Social en la Universidad de Ciencias Empresariales y Sociales. Jeannetetorrez11@hotmail.com. Teléfono: 5491130959104. Buenos Aires, Argentina.
} 


\begin{abstract}
:
This article aims to explain from a theoretical conceptual approach the particularities that exist in Victoria, San Fernando, Buenos Aires, from its urban production. Through a series of field works, semi-structured interviews and observations, it was possible to perceive that in this locality, there are three logics of city production, market, state and necessity, according to Abramo, P. (2002). The post-development cities of Latin America, a space in which constant tensions are generated that alter the harmonious development of daily life and the interaction of those who inhabit the area. On the other hand, it is also perceived that the inhabitants naturalize that way of life, their spatial disposition, the progressive privatization of public areas and the proliferation of closed housing estates. Here is a quote that we have heard repeatedly in interviews with the neighbors: "No one in Victoria gives a ball to anyone." At the moment of understanding Victoria from the theory, we take into account such concepts as the "heterotopy" of Foucault M. (1967) - understood as the juxtaposition of spaces that would be incompatible -the term "com-fusa city" (Abramo P.) - as an urban structure that interweaves two traditional models (the Mediterranean compact and the AngloSaxon diffused), the notion of "privatopia" by I.Rodriguez Chumillas (2005) and E. Mckenzie (1994) as private spatial consolidation, and finally the concepts: informative and dual cities of R Castells (1995) terms that emerge from the process of globalization, which may be useful to think about the reality of Victoria
\end{abstract}

Keywords: Com-fusa city, interaction, heterotopias, neoliberal policies, privatopías, urban reconfigurations, victoria.

\section{Resumo}

Este artigo tem como objetivo explicar a partir de uma abordagem teórico conceitual as particularidades que existem em Victoria, San Fernando, Buenos Aires, a partir da produção urbana. Através de uma série de trabalhos de campo, entrevistas semiestruturadas e observações foi possivél vislumbrar que na localidade em questão, convivem três lógicas de produção da cidade, a cidade do mercado, o Estado e a necessidade, de acordo como o concebe Abramo, P. (2002) características das cidades latino-americanas pós-desenvolvimentistas,espaço em que as tensões constantes que perturbam o desenvolvimento harmonioso da vida cotidiana e da interação das pessoas que habitam a área. Por outro lado, percebe-se também, que os habitantes tornam natural ese modo de viver, espaço disponível, a progressiva privatização de espaços públicos ea proliferação de condomínios fechados. Cita-se em seguida, uma frase que temos ouvido repetidamente em entrevistas feitas a os vizinhos: "Em Victoria ninguém espanca a qualquer um." No momento de entender Victoria a teoria leva em consideração conceitos como "heterotopia" de Foucault M. (1967) entendida como a justaposição de espaços que poderiam ser incompativeis-,o termo "cidade com - fusa" (Abramo P.,) -como estrutura urbana que junta dois modelos tradicionais (a cidade compacta Mediterrânea e difusa anglo - saxónica), a noção de "privatopia" de I. Rodriguez Chumillas (2005) e E. Mckenzie (1994) - como consolidação de espaços privados e finalmente conceitos: cidades informadas e duplas do autor R Castells (1995) termos decorrentes da globalização, que podem ser úteis para pensar sobre a realidade de Victoria.

Palavras chave: Cidade Com - fusa, interação, heterotopias, políticas neoliberais, privatopias, reconfigurações urbanas, vitória.

Cúcuta-Colombia

Vol. 1 
Cúcuta-Colombia

Vol. 1

No. 1

Jul - Dic 2016

ISSN: $2590-9215$

(En línea)

PP: $50-72$

\section{Introducción.}

La ciudad que se propone analizar en esta oportunidad es una de las tres localidades que conforman el Partido de San Fernando en el norte de la Provincia de Buenos Aires. Como se puede observar en los siguientes mapas, el Partido de San Fernando es particularmente pequeño, territorialmente hablando si la comparamos con Capital Federal por ejemplo, y más aún si lo situamos en la vasta extensión que posee la Provincia de Buenos Aires. Como dato se puede agregar que la extensión de Victoria si la recorriéramos de este a oeste es de unos siete kilómetros, pudiendo observar además que la distancia social y la distancia geográfica tienden a coincidir, donde se encuentra la mayor marginalidad en las márgenes del Rio Reconquista (este) y la mayor opulencia en las márgenes del Rio Luján (oeste).

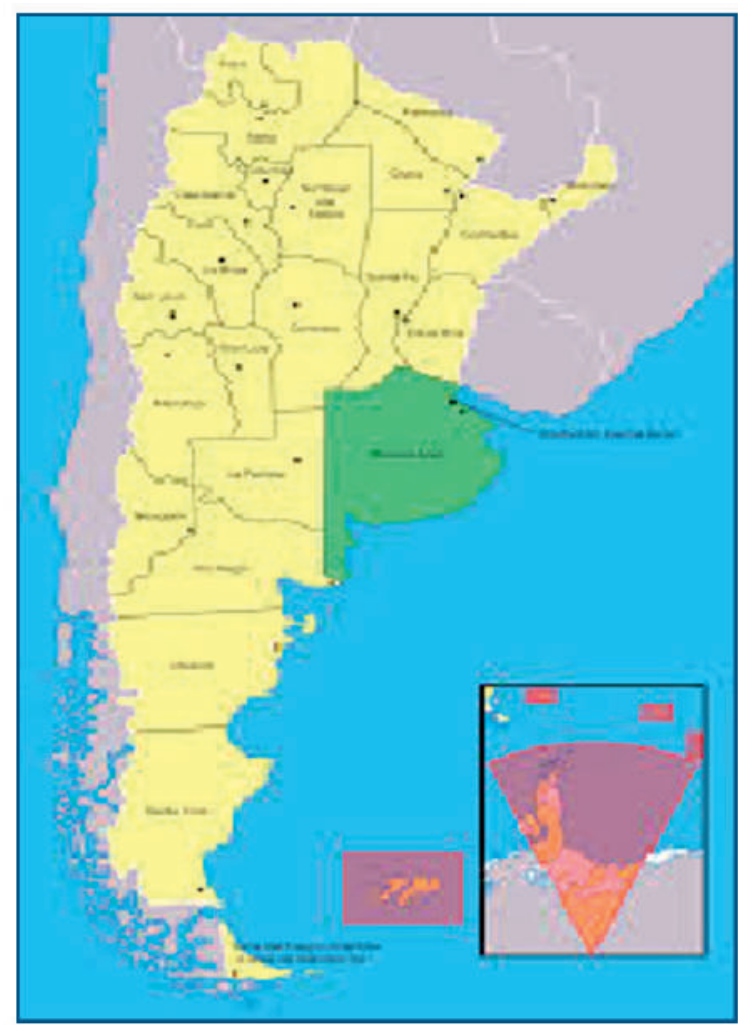

Figura 1. Mapa de la República Argentina y Provincia de Buenos Aires. Fuente: Ministerio de Educación, Presidencia de la República.
Espacio territorial en el que se yuxtaponen a lo largo de su extensión las más diversas formas arquitectónicas y disimiles producciones urbanas encontrando, si comenzamos por su margen este, grandes mansiones y casas residenciales, seguidas de barrios cerrados y privados hasta llegar a lo que se da a conocer como casco histórico, continuando con un barrio popular (Mil viviendas) para finalizar en una serie de villas y asentamientos. Todas estas formas de urbanización se encuentran conviviendo en un mismo y reducido espacio, donde varias de esas formas son producto o mejor dicho consecuencia directa del giro de la política argentina hacia el nuevo paradigma neoliberal durante los años 90 más marcadamente.

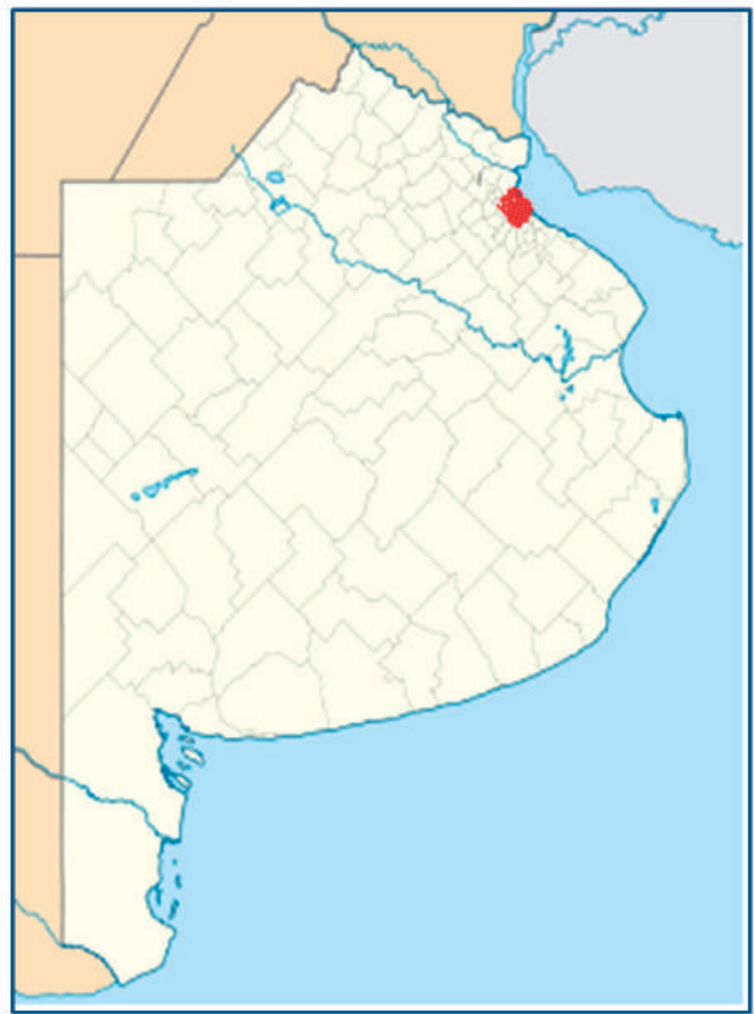

Figura 2. Mapa de la Provincia de Buenos Aires y Ciudad Autónoma. Fuente: Ministerio de Educación, Presidencia de la República. 


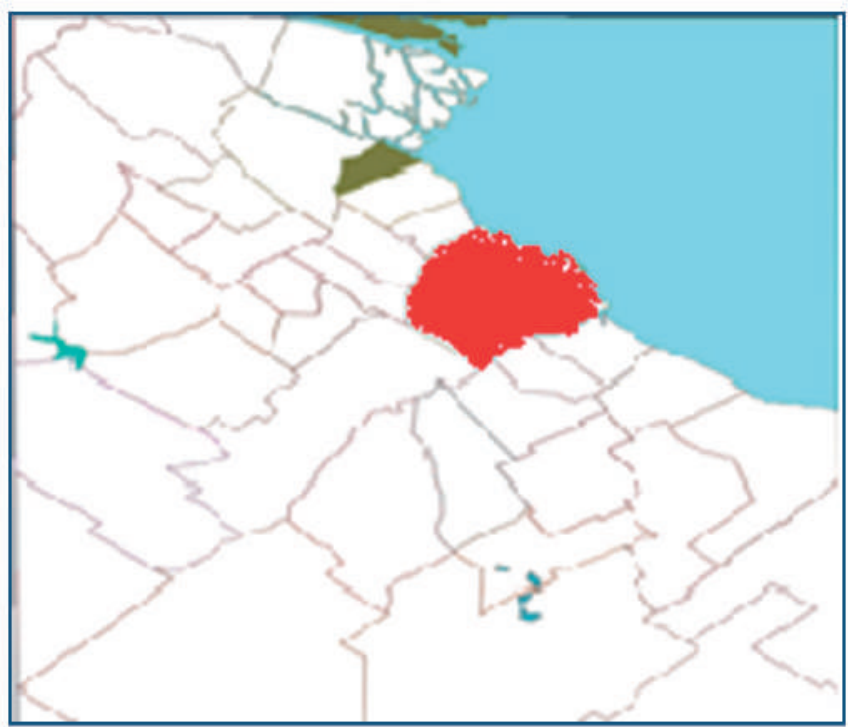

Vol. 1

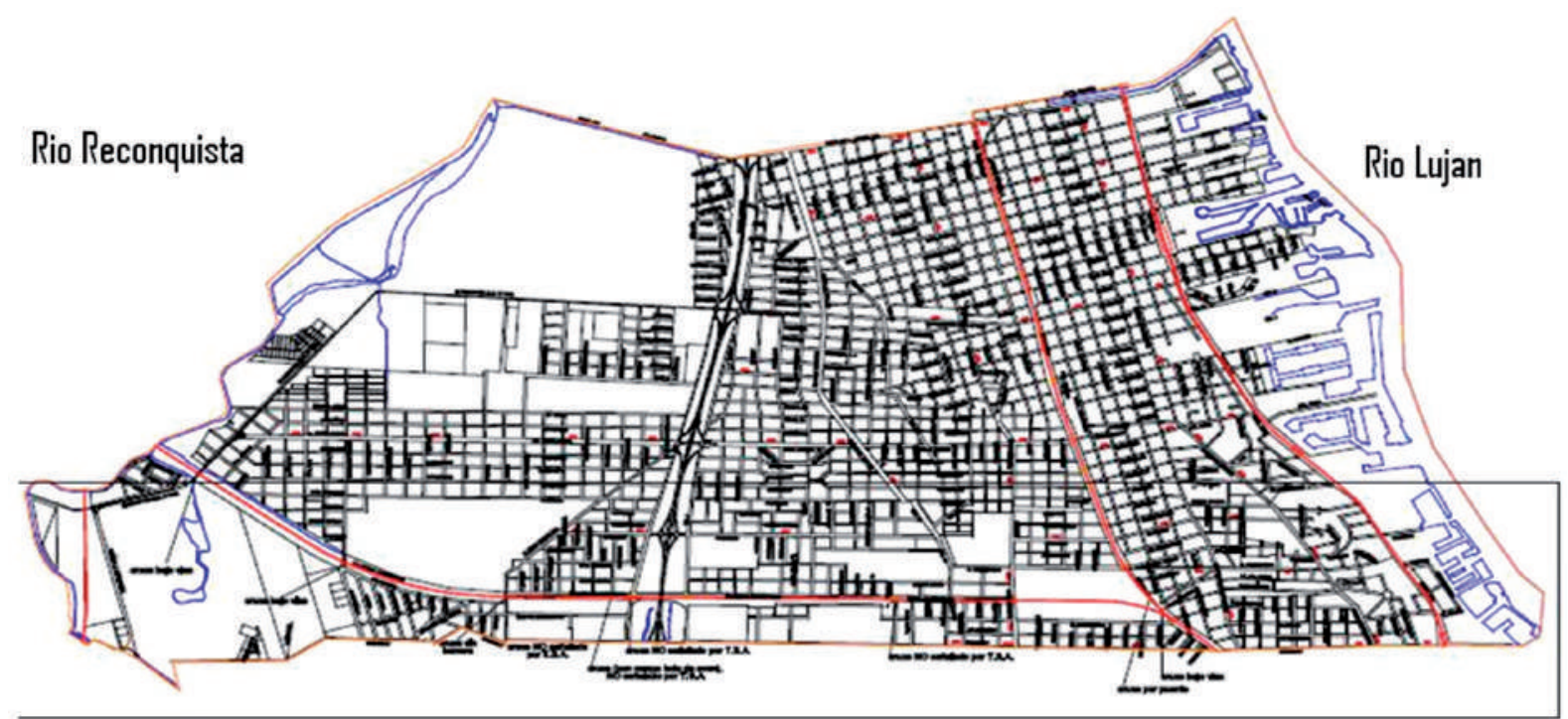

Figura 4. Área de estudio Victoria. Fuente: Ministerio de Educación, Presidencia de la República.

El surgimiento de la producción de ciudades post-desarrollistas latinoamericanas ha implicado distintos procesos de urbanización en los cuales se han entrelazado la trama urbana junto a distintos actores que fueron afectados por un conjunto de variables que condicionaron sus espacialidades así como también sus modos de vida y sus modos de interacción. Dichas ciudades han pasado a convertirse además en espacios en donde las inseguridades que fueron gestadas desde la misma sociedad se exteriorizan de una manera sólida y por ello se hacen especialmente tangibles, dando lugar a una creciente tendencia al miedo la cual deviene en la búsqueda de válvulas de escape sobre las cuales se pueda producir la descarga.

A partir de los años 70` y de acuerdo a una serie de transformaciones que se llevaron adelante en las ciudades latinoamericanas, se puede sostener que asistimos al traspaso de un modelo de ciudad abierta, asociado a un patrón europeo, centrada en el espacio público y la 
Vol. 1

No. 1

Jul - Dic 2016

ISSN: 2590-9215

(En línea)

PP: 50-72 integración social, a un modelo fuertemente marcado por un patrón norteamericano en el que se afirman valores vinculados a una ciudadanía privada, al estilo de las gated communities. En este sentido, M. Svampa (2001) señala que se han desarrollado nuevas pautas de integración, específicamente "hacia dentro", y en las que prima la mercantilización de la ciudadanía.

En Victoria, antes del despliegue de las políticas neoliberales, existían modelos de socialización basados en la integración social a través de la heterogeneidad social y residencial, en los que se articulaban relaciones al interior de un grupo social y relaciones entre otros grupos de la estructura social. Podemos afirmar que el papel del barrio, la escuela pública, las plazas, las zonas costeras, cumplían la función de pautas de socialización "igualitarias". Los años 90" se caracterizaron por el impulso a un proceso de reestructuración del Estado que implicó una significativa reducción del gasto público en las áreas sociales, la descentralización administrativa, la desregulación de los mercados, la privatización de empresas nacionales y la introducción de nuevas formas de organización del trabajo signada por la flexibilización y precariedad laboral además de un marcado crecimiento del desempleo, que constituyó un nuevo marco social caracterizado por un fuerte proceso de polarización donde todas las clases sociales padecieron significativas transformaciones. Dichas medidas que se desprenden al vaciamiento y la decadencia de los servicios estatales, dando como resultado la reconfiguración del paisaje urbano, en el cual los ganadores de este proceso eligieron autosegregarse en urbanizaciones cerradas y los que perdieron no les quedó más opción que enfrentar las consecuencias de la desafiliación en el marco de una ciudad excluyente que los relegó a espacios segregados, entendemos que el neoliberalismo constituyó un nuevo marco

social caracterizado por un fuerte proceso de polarización donde todas las clases sociales padecieron significativas transformaciones. El proceso socioeconómico neoliberal reconfiguró también, por supuesto, el paisaje urbano (Svampa, M., 200, pp.260-265).

La privatización progresiva de los ámbitos públicos y las pautas de socialización que se coligaban a los barrios sufrieron el avance de dichas políticas, siendo producto de ello el advenimiento de un proceso de segregación residencial como símbolo de fragmentación social excluyente. El desmantelamiento del Estado Social, limitó las capacidades de gestión estatal urbana y las estrategias de planeamiento se vieron fuertemente afectadas terminando en el abandono de la infraestructura pública por parte de la administración, agudizando de éste modo la brecha entre ricos y pobres por la decreciente capacidad redistributiva del Estado. Polarización ésta que llevo a una reconfiguración espacial, en donde aquellos habitantes que poseían cierto grado de posibilidad de acceso comenzaron a optar por habitar en organizaciones privadas $y$ eficientemente fraccionadas de la vecindad con pautas de control reforzadas, plasmadas en distintos modelos de ciudades, de esta manera surgen enclaves de riqueza como las urbanizaciones cerradas y enclaves de pobreza, como las villas y asentamientos. Si bien esto no representa ninguna novedad en nuestro país, lo que sucede luego de la última dictadura militar y se profundiza a finales de los años 80 y posteriores, son procesos cada vez más marcados de desigualdad socioespacial. Siguiendo el análisis de Daniela Soldano (2014) respecto al conjunto de transformaciones económicas, políticas y sociales que sucedieron desde los años setenta, la autora remite a los principales cambios ocurridos en la fisonomía de la cuestión social en nuestro país: la instalación de la pauperización, la retracción o pérdida de efectividad de los sistemas de protección social asociados a la integración salarial, 
la diferenciación de los sectores sociales y la fragmentación del espacio urbano. El conurbano bonaerense ${ }^{1}$ no sólo encarnó este proceso de cambio social sino que lo tradujo espacialmente:

En especial en sus periferias donde se produjo una acentuación de la segregación residencial, protagonizada tanto por los barrios que se crearon y "encerraron " por propia voluntad, minimizando intencionalmente los contactos con el entorno, como por aquellos que fueron siendo "encerrados" a partir de la yuxtaposición de dinámicas estructurales de relegación socioeconómica y de aislamiento espacial (Soldano, 2014, p.14).

Pues bien, dicho abandono por parte del estado, acompañado de una apropiación proveniente de los actores privados da como resultado el surgimiento de nuevas formas urbanas comercializables y de un gran valor para el mercado inmobiliario. Llamativamente se observó que Victoria paso a ser una ciudad en donde solo sus habitantes viven, entendiendo a vivir como el lugar donde poseen sus hogares, ya sea por elección o por herencia, pero no es dicha ciudad un lugar donde gasten sus tiempos libres, donde busquen el ocio y la recreación aun tampoco es un lugar donde la mayoría de sus habitantes trabaje, todo ello lo hacen fuera de los límites de Victoria.

Todo ello desemboca en las particularidades de las ciudades de hoy, las cuales distan de ser un lugar amable y confortable donde los ciudadanos puedan coincidir o conversar libremente. Por lo menos en Victoria, las calles, las plazas, los parques han dejado de ser lugares de encuentro, de interacción, de coexistencia y de relaciones sociales para convertirse en lugares de paso, de fugacidad, de necesidad. En este contexto el Estado concreta el pasaje a un modelo basado en una estrategia aperturista.

Se entiende como conurbano bonaerense a los 24 partidos que rodean a la Ciudad de Buenos Aires.
Como se viene mencionando, Victoria no es la excepción al caso y despertó nuestra atención debido a que mediante una serie de observaciones en el campo y de la realización de entrevistas semi-estructuradas a vecinos de la ciudad de diferentes edades y condiciones socioeconómicas se pudo vislumbrar la existencia de una convivencia que aparece en un primer acercamiento como beligerante, es decir, un espacio en el que se generan constantes tensiones que alteran de alguna forma el desarrollo armónico de la vida cotidiana y la interacción de quienes habitan la zona. Es por ello que en el intento de pensar o mejor dicho entender de qué tipo de ciudad se habla cuando se menciona a Victoria se considera que hay algunos conceptos que pueden ayudar a comprender sus particularidades, tales como heterotopía, privatopía, ciudad com-fusa y ciudad dual e informativa, los cuales serán desarrollados más adelante.

Ahora bien, retomando el cambio de paradigma, en Victoria se encuentran aún hoy, huellas del modelo de Industrialización por Sustitución de Importaciones (ISI), donde prevalecen como principal elemento estructurante de la morfología urbana, los emprendimientos productivos de tipo fabril de capitales nacionales en alianza con políticas públicas de transporte, vivienda, gestión del suelo y educación. Ejemplo de ello es la empresa de capitales nacionales de neumáticos Fate y el barrio obrero homónimo el cual construyó sus casas y porque no su identidad en función de la fuente de trabajo.

Por otro lado se puede afirmar que Victoria es afectada por una transformación común a las ciudades latinoamericanas, en donde el principal cambio está relacionado con los actores dinamizadores de ciudad en donde si anteriormente se erigía el Estado en su nivel nacional como el gran planificador en materia socio-territorial, de vivienda, transporte, educación y salud, en los
No. 1

Jul - Dic 2016

ISSN: 2590-9215

(En línea)

PP: $50-72$ 
Vol. 1

No. 1

Jul - Dic 2016

ISSN: 2590-9215

(En línea)

PP: $50-72$ años 90` estas cuestiones recaen sobre el mercado, en particular aquellos vinculados con los servicios (inmobiliarios, seguros) y vinculados al consumo (centros comerciales, ocio).

Al momento de "producir la ciudad" y tal como lo concibe Pedro Abramo (2002) se presentan tres lógicas, las cuales corresponden temporalmente o coinciden con la conformación de las ciudades postdesarrollistas latinoamericanas la cuales son el producto de la crisis fordista urbana. Crisis que podemos ver materializada en la primacía de la flexibilización urbana por sobre el urbanismo regulador y en la caída del financiamiento estatal de la materialidad de las ciudades (refiriéndose con esto último al financiamiento para viviendas, infraestructura y equipamiento, además de servicios urbanos colectivos).

Momento que se corresponde no solo con el corrimiento de la lógica del Estado, sino también con el advenimiento del mercado (otra de las lógicas) como principal coordinador de la producción de ciudad (comercial y residencial). Ya sea por medio de la privatización de empresas estatales o por medio de capital privado hegemónico. El mercado pasó a constituir el rasgo característico de la ciudad neoliberal.

Es la lógica del mercado la que prima como principal y hegemónico mecanismo en cuanto a la coordinación de las decisiones de los usos del suelo, produciendo una estructura o forma de ciudad particular y característica de América Latina: una estructura "híbrida" desde el punto de vista de su morfología de usos del suelo, vis à vis a los modelos tradicionales de la ciudad moderna. (P. Abramo, 2012, pp.35-36)

La lógica de la necesidad, es la tercera de ellas, la cual responde a una serie de acciones individuales y colectivas las cuales mediante el ciclo de ocupación primero y autoconstrucción después culminan en la consolidación de los asentamientos populares informales. Dichas lógicas se yuxtaponen en un mismo terreno, dando como resultado una alteración de la armonía, a escala arquitectónica y en tanto relaciones sociales. Lo que Foucault ha dado a llamar heterotopía, término que será desarrollado más adelante.

Ahora bien, es central la Lógica del Estado al hablar de producción de ciudades, teniendo en cuenta que es la única de las tres que posee el poder necesario para ejercer la regulación sobre las otras dos, limitando el avance de la especulación que existe en torno al mercado inmobiliario por un lado y proveyendo las soluciones adecuadas, de acuerdo a las necesidades de los sectores más vulnerables en materia habitacional por el otro. A su vez, es también el Estado quien: mediante regulaciones y políticas provee de maneras variadas el sustento para el despliegue de las otras dos formas de producción de ciudad (mercado y necesidad) (Herzer, et.al., 1994. pp120). Entonces se asienta que es por medio de políticas de vivienda, ciertas normativas, el diseño y la posterior implementación de las mismas que el Estado resuelve o agudiza el problema del acceso a la vivienda para los sectores populares, entendiendo a dichas políticas como un conjunto de tomas de posiciones que reflejan una cierta filosofía política y una concepción sobre el modo en el que deben resolverse determinadas cuestiones sociales (Oszlak, 1991), para no caer en un reduccionismo que las coloca en el lugar de una mera voluntad estatal.

Para el caso de Victoria ésta trilogía de lógicas pueden ser observadas en su entramado urbano en toda su extensión en el que se destacan:

- Lógica del mercado, plasmada en la construcción de barrios cerrados como Las Victorias, La Chacra y El Trébol a partir del desembarco de políticas neoliberales. 
- Lógica del Estado, Barrio Mil Viviendas, el cual consta de monoblocks organizados por manzanas que alojan a un número importante de habitantes, creado bajo iniciativa estatal.

- Lógica de la necesidad, Villas Santa Rosa, Villa Uruguay de casas humildes y precarias, en tanto movimiento de acciones individuales y colectivas que desembocan en el establecimiento de "ciudades populares"

La existencia de las mismas todas juntas desembocan en una alteración de la armonía, tanto a niveles arquitectónicos como en cuanto al desarrollo de las relaciones sociales.

\section{Recursos materiales y métodos.}

La investigación que se dispuso llevar adelante puede ser ubicada dentro del paradigma mixto de investigación, teniendo en cuenta que el trabajo que se realizó tiene que ver con poder describir que tipo de ciudad es Victoria desde diversos conceptos que se adecuan a ella y a partir de la observación del campo así como también desde la percepción que tienen los vecinos que la habitan, pero sin dejar de contemplar datos cuantitativos que se tornan significativos al momento de hacer analogías entre Victoria y otras localidades de Buenos Aires, los cuales permiten vislumbrar las transformaciones mencionadas. Se habla de la elección del paradigma mixto de investigación con bases en las concepciones de Creswell y Plano (2007) quienes sostienen que el plan de acción posibilita la combinación de técnicas propias de ambos métodos para la recolección y análisis de datos. Cabe señalar que estos autores establecen una clara delimitación entre los conceptos de metodología, diseño y método. La metodología es asumida como una estructura filosófica y por tanto, presupuesto fundamental relacionado con todo el proceso de investigación; el diseño corresponde al plan de acción que enlaza la estructura metodológica con el método, este último más asociado a los instrumentos específicos de recolección y análisis de datos. Los métodos mixtos son un diseño de investigación tanto con unos presupuestos epistemológicos como con unos métodos de investigación. Como metodología supone presupuestos filosóficos que orientan la recolección y análisis de datos y la combinación de aproximaciones cualitativas y cuantitativas en muchas fases del proceso de investigación. Como método, se enfoca en la recolección, análisis y combinación de datos cualitativos $\mathrm{y}$ cuantitativos en un estudio o una serie de estudios (p.5).

Cabe destacar que hablar con vecinos de Victoria que representen a los diferentes estratos sociales que allí confluyen no fue tarea fácil, ya que por parte de los sectores más altos el dialogo y hasta el acceso a sus barrio fue imposible, por la reticencia y el rechazo que presentaron al momento de proceder a la pertinente presentación de quienes éramos y que nos encontrábamos haciendo en Victoria.

Dicha localidad despertó la atención desde la primera fase de la investigación, es decir desde una serie de salidas al campo a puntos clave de la localidad, léase con esto: la zona costera, los barrios privados, el barrio Fate, el barrio Mil Viviendas, la villa Santa Rosa y su casco histórico, donde sucesivas observaciones dejaron contemplar los conflictos que la azotan.

Ya en una segunda fase, se realizaron algunas entrevistas semiestructuradas que permitieron confirmar la existencia de una convivencia que aparece en un primer acercamiento como beligerante gracias a las disimiles producciones urbanas que allí se disponen, es decir un espacio en que se generan constantes tensiones que alteran de alguna forma el desarrollo armónico de la vida cotidiana y la interacción de quienes habitan la zona. Una tercera fase consistió en analizar las observaciones realizadas y decodificar las entrevistas, lo que permitió tener una idea
No. 1

Jul - Dic 2016

ISSN: 2590-9215 (En línea) PP: $50-72$ 
Vol. 1

No. 1

Jul - Dic 2016

ISSN: 2590-9215

(En línea)

PP: 50-72 más clara sobre la localidad para así poder pensar o mejor dicho entender de qué tipo de ciudad se hace referencia cuando hablamos de Victoria. Por ello se considera que hay algunos conceptos que pueden ayudarnos a comprender sus particularidades, tales como heterotopía, privatopía, ciudad com-fusa y ciudad dual e informativa, los cuales serán ampliados más adelante.

Es pertinente destacar que a lo largo del presente trabajo se hace mención a dos tipos de urbanizaciones que se han desarrollado de manera significativa conjuntamente con el cambio hacia el paradigma neoliberal, y con esto nos referimos a las villas-asentamientos y los barrios privados-cerrados. Entonces, si bien a lo largo de la investigación, se van explicitar características de los mismos, consideramos que un análisis más profundo de cada una de estas formas urbanas implica un trabajo de investigación aparte.

\section{Resultado.}

\subsection{Lógicas del mercado y fragmentación}

La aplicación de las políticas neoliberales antes mencionadas sobre la Argentina trajeron consigo serias consecuencias a escala económico-social en donde el principal efecto de ésta reestructuración fue que gran parte de los sectores sociales medios y bajos perdieran la posibilidad de acceder a un trabajo digno y a una vivienda decente, además de perder toda clase de beneficio social, incrementando con ello los niveles de pobreza, indigencia y exclusión. Las políticas estatales fueron las responsables de los retrasos sistemáticos de la inversión en obra pública y del deterioro de la infraestructura social básica o simplemente incumpliendo la promesa de desarrollo en sus regiones históricamente relegadas. Las intervenciones económicas del Estado también fueron responsables plenas de la instalación de la pobreza y de la vulnerabilidad como lógica organizadora de la vida diaria en los barrios.
En tanto, a la mencionada situación coyuntural político-económica se le agregó una progresiva sensación de peligro $\mathrm{y}$ de inseguridad fuertemente alimentada por medios de comunicación masivos, que comenzó a primar en la sociedad especialmente en las clases medias-altas con cierto poder adquisitivo. Sector de la estructura social que asistió de forma voluntaria a la segregación espacial gracias a su condición de "ganadores" (Svampa, M. 2001, p. 15-16) en el marco del ajuste. En el caso de Victoria esto se ve en el surgimiento de barrios privados como La Chacra, Las Victorias y El Trébol.

Además de la ampliación de la desigualdad social, el sentimiento de lograr una homogeneidad social y un estilo de vida diferente, (lo que se puede catalogar como cambios estructurales) se conjugan en ésta nueva construcción de un espacio a habitar. Pero no es solo eso, sino que del mismo modo, la decisión de los actores sociales a segregarse en un barrio cerrado (o de segregar a los demás) es otro de los motivos que dan cuenta del surgimiento de una nueva categoría de segregación especial: la auto-segregación, que obedece a un fenómeno voluntario de acuerdo a las expectativas, elecciones y ambiciones que poseen los individuos.

Por eso decimos, que la inseguridad ciudadana, el miedo a la violencia, el sentimiento de vulnerabilidad al problema social y la incapacidad del Estado de asegurar ciertos servicios considerados básicos gracias a la retracción del mismo en áreas sociales, precipitó la aceleración y consolidación de los estratos altos hacia las urbanizaciones cerradas.

En Victoria ésta polarización se puede observar a lo largo de toda su extensión donde encontramos que los distintos tipos de urbanizaciones lindan continuamente. Los barrios cerrados (La Chacra, El Trébol, Las Victorias) a partir de la década de los $90^{\prime}$ pasaron a constituir parte del paisaje 
cotidiano, transformando el panorama urbano donde las murallas y los dispositivos de seguridad actúan como símbolos de status y distinción,

Algunas personas deciden vivir en un barrio cerrado porque buscan tener relaciones más cercanas con gente perteneciente al mismo grupo socioeconómico $\mathrm{y}$, además, buscan evitar la heterogeneidad social que suele darse en los barrios "no cerrados", como así también, todo contacto con situaciones de pobreza y extrema miseria, tan usuales actualmente en las ciudades de hoy (Caldeira en Bauman, 1997, pp, 107-110).

Es reveladora la adopción de comportamientos de los habitantes del barrio cerrado La Chacra, que buscan diferenciarse tajantemente de los "sectores populares" que habitan en el Barrio Mil Viviendas (Barrio popular construido allá por 1993 y culminado en 1999, bajo iniciativa estatal en conjunto con el Sindicato de Empleados de Comercio primero y conjuntamente con la Policía de la Provincia de Buenos Aires después) marcando distancias desde lo arquitectónico a través de la construcción de muros divisores, tendido de cerco electrificado, redes que se extienden sobre los muros y en algunos casos la ruptura se puede visualizar hasta en la inexistencia de aceras adecuadas para la libre circulación, así como también el veto al acceso libre a este tipo de urbanización.

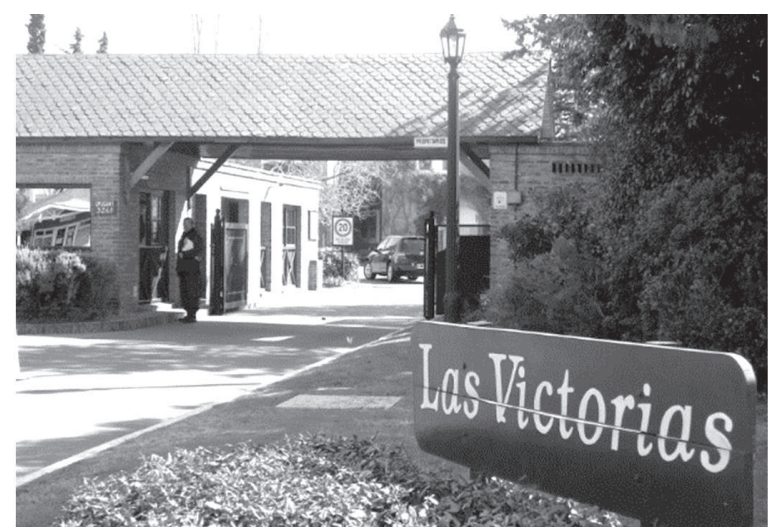

Figura 5. Barrio Cerrado Las Victorias, Simil del Barrio Cerrado La Chacra.

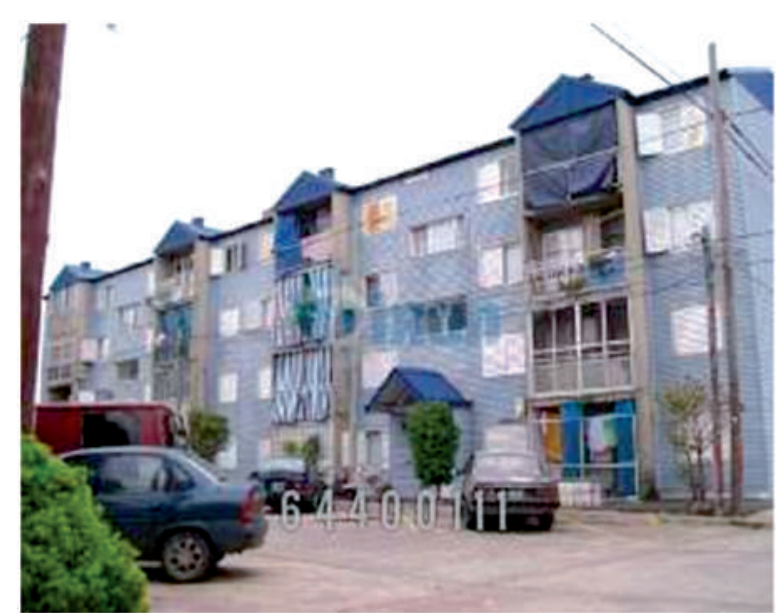

Cúcuta-Colombia

Vol. 1

No. 1

Jul - Dic 2016

ISSN: 2590-9215

(En línea)

PP: 50-72

Figura 6. Barrio popular Mil Viviendas.

En relación a esta cuestión, Flusty (1997) quien basa alguna de sus trabajos en la enumeración de innovaciones en materia de arquitectura y urbanismo, asegura que las murallas que se erigen hoy en día tienen como finalidad mantener separados a los distintos tipos de ciudadanos ( los barbaros de los civilizados) y a su vez lejos de los problemas sociales existentes. Dicho autor cita una variedad de espacios vetados, tal como él llama a los diferentes artilugios arquitectónicos, en donde podemos encontrar según su clasificación desde espacios escurridizos, los cuales son inaccesibles debido a las complicadas vías de acceso que se presentan como tortuosas, escabrosas y hasta inexistentes, los espacios espinosos que datan de sectores que no pueden ser ni ocupados ni utilizados cómodamente, llámese salientes y pendientes y los espacios nerviosos que nos hablan de la existencia de una vigilancia permanente que no permite pasar inadvertidos, con tecnologías de control y centro de monitoreo, siendo dichos espacios tienen como propósito disociar los enclaves extraterritoriales de la continuidad del territorio urbano, o mejor dicho:

Erigir pequeñas fortalezas compactas en cuyo interior los miembros de la elite global supraterritorial pueden cuidar, cultivar y gozar de independencia física, sumada a la espiritual y de su 
Vol. 1

No. 1

Jul - Dic 2016

ISSN: 2590-9215

(En línea)

PP: 50-72 aislamiento geográfico. En el paisaje de la ciudad, los espacios vetados se han convertido en los hitos de la desintegración de la vida comunitaria compartida de una localidad" (Flusty, en Bauman, 1997, pp.112-113).

En Victoria estos tipos de espacios se hacen presentes, por ejemplo en la falta de aceras en los laterales de los barrios privados, como se mencionó más arriba, en las zonas costeras privatizadas y las zonas lindantes a los barrios cerrados respectivamente, donde se hacen presente todo tipo de tecnologías de control tal como lo menciona el autor.

Mecanismos estos que lo que buscan es lograr cierta distancia de lo extraño, de lo peligroso, configurando de esta manera el aspecto más visible de las ciudades contemporáneas, donde diseñadores y arquitectos se esfuerzan por poner en sintonía sus creaciones con el paisaje urbano. Ahora bien, la experiencia ha demostrado a lo largo de sucesivas investigaciones y estudios que estos subterfugios no disminuyen el riesgo así como tampoco disminuyen los índices de delitos, sino que paradójicamente, acentúan la sensación de inseguridad y miedo incrementada por la paranoia y la desconfianza.

Desde La Chacra, los altos muros que tapan las ostentosas viviendas, generarían la rabia de quienes viven en el barrio Mil viviendas $\mathrm{y}$ en donde estos, en un intento de hacerse visibles arrojarían toda clase de objetos hacia el interior del barrio. Por su parte desde La Chacra, se intensifican las medidas de seguridad, levantando alambrados a alturas inalcanzables, así como también refuerzan su seguridad en materia de electrificaciones y alambrados con púas. Las tensiones en esa zona son constantes, la violencia se manifiesta desde ambas partes tanto implícita como explícitamente en cuanto a las representaciones sociales que cada actor posee del otro.
En el marco de esta concepción, Gumpert y Drucket (1996) sostienen que hoy en día existen alrededor del mundo una cantidad de espacios urbanos cerrados que tienen como función principal la protección de sus habitantes y no así la integración de las personas a la comunidad, vislumbrando de este modo que la segregación y el apartamiento "es la estrategia más habitual en la lucha urbana por la supervivencia" (Gumpert y Drucket, 1996, p.105) Lucha que trae aparejada una extrapolación, en donde los habitantes con bajos recursos se van en muchas ocasiones obligados a correrse a zonas que se encuentran en las afueras de las áreas amenas y agradables de las ciudades, dando lugar a la conformación de guetos urbanos involuntarios, pero al mismo tiempo quienes se encuentran en una situación económica privilegiada, si se le puede llamar así, optan por residir en barrios apartados coincidiendo con el proceso de guetización pero esta vez voluntario. En el caso de Victoria, como su extensión es tan reducida, las áreas amenas colindan con las áreas que no lo son, dando lugar a la existencia de una convivencia conflictiva entre los sectores altos y los medios, medios-bajos ya se disponen en el mismo espacio geográfico.

Contribuyendo con estos aportes, Nan Ellin (1995), asegura que desde la "arquitectura del miedo" surgen los cimientos en la construcción de la ciudad globalizada, en donde se puede vislumbrar la carencia de vitalidad, la existencia de una actitud defensiva, la exhibición del temor hacia el entorno, las cuales determinan la necesidad de crear una maquinaria que permita dar con la certidumbre de la seguridad. El miedo como factor determinante y condicionante de la vida urbana está íntimamente emparentado con la incursión de la sociedad industrial en la modernidad cuyo andamiaje es la premisa del cambio permanente, cambio que termina propiciando la misma inseguridad. La globalización como fenómeno de interacción e 
integración a escala internacional, ha encogido el espacio público y con ello ha dilatado cada vez más la brecha entre ricos y pobres, desalentando los espacios de coexistencia. Tal como sostiene la retribalización de la sociedad, así como también el reagrupamiento intencional con el fin de preservar las diferencias, son fenómenos que avanzan paralelamente y unidireccionalmente con la idea de inseguridad que se vio acelerada por el rápido desarrollo del cosmopolitismo en expansión.(p.111)

En materia de representaciones sociales ${ }^{2}$, el desconocimiento de la existencia del "otro" también es parte de la falta de interacción, acentuando de éste modo la grieta social, y en este sentido, relevamos que habitantes de Mil Viviendas, que se ubican al otro extremo de la manzana, sostienen no saber que uno de los laterales de su complejo habitacional tiene como vecino al barrio cerrado La Chacra. Sin embargo, pudimos relevar a través de algunas entrevistas que sí existe un reconocimiento del otro por parte de quienes habitan el barrio cerrado, pero que aparece como negativizado al momento que se hace presente como el causante en cuanto a la decisión de intensificar las medidas de seguridad con el fin de lograr mayor seguridad y una vida más tranquila.

Cabe aclarar que cuando se hace referencia al concepto de interacción se hace retomando los estudios de Goffman, quien desde el interaccionismo simbólico estudió las unidades mínimas de interacción entre las personas en grupos reducidos, focalizándose en la influencia de los significados y los símbolos sobre la acción y la interacción humana, son de suma utilidad. Retomamos su definición diciendo que la interacción social puede definirse en sentido estricto como aquella que se da exclusivamente en las

\footnotetext{
2 _ Las representaciones sociales según Moscovici,..." aparecen ante nosotros como una acción psicológica, una modalidad de conciencia particular, que posee una función simbólica ya que de manera implícita contienen un significado que se encuentra íntimamente relacionado con la situación del sujeto frente al contexto en el que habita y con el cual se relaciona".( Moscovici, 1961)
}

situaciones sociales, es decir en las que dos o más individuos se hallan en presencia de sus respuestas físicas respectiva (Goffman en $\mathrm{M}$. Maldonado y L. Contreras, 2011, p.167).

Para dicho autor, los individuos encuentran su vinculación con la sociedad por medio de dos vías fundamentales, por un lado como miembros que conforman una colectividad ya sea por edades, profesiones, géneros, etc. y por el otro por las relaciones sociales que entablan con otros individuos, donde la comunicación pasa a ser el elemento fundamental que como mecanismo, regula y hace posible dicha interacción.

Por su parte, y desde un punto de vista más urbano, al abordar las interacciones, Simmel hace referencia a que las mismas pueden ser momentáneas o permanentes, conscientes o inconscientes, superficiales o profundas, pero conservan de manera constante el vínculo entre los hombres. A cada instante estos lazos de relación se prolongan, se rompen, se retoman nuevamente, se suplantan por otros, se entrelazan con otros. Sostiene además que la sociedad es una compleja red de interacción social e interdependencia. Podemos agregar también que según el autor, la interacción encierra reciprocidad en tanto conducta en retorno, confiriéndole a las mismas la consideración de la existencia del otro.

Ahora bien, Simmel (1908) quien se centra en la función del entramado urbano desplazando el análisis de las ciudades desde los datos estructurales o económicos a la arena de las relaciones sociales con énfasis en las formas a través de las cuales éstas eran creadas por las generaciones de los urbanitas tal como lo menciona Bettin (1982, p.82). Para él, la ciudad aparece como un campo de acción sobre el cual los individuos establecen relaciones conforme al constante cambio de estímulos, de especialización y de racionalización.

Más allá de la ciudad como estructura material, como realidad objetiva $\mathrm{y}$ 
Vol. 1

No. 1

Jul - Dic 2016

ISSN: 2590-9215

(En línea)

PP: 50-72 tangible de una organización espacial de la sociedad que no puede ser negada se desarrolla el campo de relaciones sociales que hacen de este lugar la urbs (Delgado, 1999, p 17-19)

De acuerdo a lo mencionado anteriormente, la interacción como parte constitutiva de la socialización, cumple un papel fundamental en la construcción de las personalidades, de las identidades y las representaciones que poseen quienes habitan un espacio en común, de allí su importancia y por lo tanto su estudio. Cabe desatacar que cuando se decidio abordar la problemática de la interacción en ese espacio urbano, se pensó primeramente analizarla en relación a los diferentes diseños urbanísticos que se disponen en dicha localidad. Ahora bien, con el paso del tiempo y el avance en la recopilación de información, pudimos observar en contraste con el primer supuesto, que la carencia de interacción no es una problemática que necesite de dos modelos de ciudad contrapuestos, sino que dentro de espacios que a simple vista aparecen como homogéneos, de acuerdo a ciertas dimensiones, también la ausencia de interacción entre sus miembros se hace presente. Particularidad que encuentra íntima ligazón con cuestiones que son netamente arquitectónicas. En tal sentido se puede decir que la disposición arquitectónica de un espacio dado tiene su repercusión en el desarrollo de la vida de las personas que lo habitan afectando sus formas de vida y sus predisposiciones para establecer relaciones sociales o conflictos. La arquitectura es un elemento fundamental de estudio, debido a que el estilo de una construcción puede fomentar o no el desarrollo de la comunicación de los habitantes de un lugar, siendo esta última indispensable para la interacción entre pares. Dicha situación encuentra su ejemplo en el ya mencionado Barrio Mil Viviendas en donde mediante una observación de campo se pudo apreciar que dentro de cada manzana como espacio de sociabilización o esparcimiento solo se encuentra un jardín de poca extensión y una parrilla. El barrio no incluye ningún tipo de construcción no solo que promueva la interacción entre quienes lo habitan, entiéndase lugares de ocio y entretenimiento como podría ser una plaza o espacios culturales, así como tampoco incluye construcciones que se relacionen más con el desarrollo y la vida cotidiana de las personas, entendiéndose para éste caso, la existencia de escuelas, salas de primeros auxilios, polideportivos. Más aún se puede observar la ausencia de aceras bien delimitadas y lo suficientemente amplias donde poder caminar, lo que deriva en la utilización de lo que conformaría " las calles" (teniendo en cuenta que allí se ubican las cocheras) como lugar de tránsito de los peatones quienes se mueven en manera dispersa.

Cabe destacar que la arquitectura como una disciplina más entre tantas otras, no se ubica por fuera de sesgos valorativos ni de posiciones ideológicas, de allí la existencia de tan disimiles espacios urbanos y sus diferentes intencionalidades. Ahora bien, luego de la breve aclaración en tanto el concepto de interacción y retomando la cuestión de la otredad se enuncia que la apreciación de un "otro" que aparece como negativizado, como parte constitutiva de la ciudad residual, sería el causante en cuanto a la decisión de intensificar las medidas de seguridad con el fin de lograr mayor salvaguarda y una vida más tranquila. El agrupamiento en relación al interés de "preservar diferencias", es un fenómeno análogo al fenómeno de la inseguridad de acuerdo a los acelerados procesos del cosmopolitismo en expansión.

Ahora bien, entre los efectos sociales que se pueden identificar que producen los barrios privados en Victoria, se ha observado que contribuyen al establecimiento de una división clara en un espacio uniforme entre "los de adentro" y "los de afuera", efecto éste que moldea las representaciones en el tejido social, 
además de exhibir cierto sesgo de intolerancia por parte de "los de adentro" para con los problemas sociales de "los de afuera". Es por ello que los barrios cerrados se presentan como un caso extremo de segregación social urbana al ser ésta manifiesta y evidente. Por ende los que residen adentro desarrollan sus vidas fuera de la vida de la ciudad, la cual se presenta como despreciable, desconcertante, inquietante $\mathrm{y}$ peligrosa por motivo de su desorden y su dureza, enclaustrándose en lo que sus habitantes consideran como un oasis en medio de tanto caos, por su tranquilidad y seguridad. Sus mecanismos de seguridad no solo son barreras físicas sino también barreras sociales que establecen límites en el tejido social. La novedad de la segregación residencial es, su intensidad, visibilidad y explicitud además de ser uno de los resultados del proceso de fragmentación social urbana. Tal como sostiene Z. Bauman, (2007) la materialización de las murallas da como resultado la fragmentación entre el gueto voluntario de los poderosos de los guetos involuntarios y forzosos en los que viven los desheredados (p.110). La comunidad cerrada como elemento común muestra que las formas espaciales cerradas sirven para delimitar, agrupar, separar. Delimitan partes de la ciudad, deslindando sectores urbanos servidos; agrupar socialmente según capitales económicos, sociales, culturales y simbólicos (Bourdieu, 2000, p.14).

Se insiste en destacar el nivel de fractura social que existe en Victoria, el cual ha despertado la preocupación de instituciones del Estado Nacional, entre ellas, la Subsecretaría de Planeamiento Urbano. La cual, junto a un grupo de expertos, en los que se destaca el Arquitecto Eduardo Reese ${ }^{3}$, elaboraron un nuevo Plan de Desarrollo Urbano, argumentando la necesidad de tomar acción frente a la problemática del "contraste socioespacial", la "población vulnerable"

3 Prestigioso arquitecto Argentino, recibido en la Universidad de La Plata, especialista en Planificación y Gestión Urbana afectada por las "inundaciones", "el ascenso de napas" y "déficit de áreas verdes públicas recreativas".

\subsection{Nuevo paradigma neoliberal.}

El giro hacia el nuevo paradigma neoliberal queda explícito en las entrevistas llevadas adelante, donde no solo la percepción sino también las experiencias personales dan cuenta de los cambios sufridos en dicha ciudad.

"Mirá, te digo, Victoria antes era totalmente distinto, totalmente distinto [con énfasis]. Las clases sociales, todos se unían, a través de las escuelas. En los colegios nacionales vos tenías de todo. Pero ahora los de estas zonas, los de punta chica y toda esta zona de plata, ya mandan a sus hijos a colegios privados y ahí ya no tenés contacto. $Y$ Victoria, es una cosa de las vías a la costa y de las vías para el otro lado. Hacia la zona de la estación del otro tren [refiriéndose al Mitre], todo eso es clase media-media. Después, de las vías para el otro lado es clase media-

baja o baja. Pero para este lado tenés toda la gente de plata. Antes todo esto [refiriéndose a la zona costera] era totalmente distinto, cambió todo en los '90 con Menem ${ }^{4}$. Antes esto era una belleza, una preciosura [refiriéndose a la zona costera]. Y Menem hizo unos negociados..." (Hombre de 69 años, vecino de Victoria)

El entrevistado identifica un marcado punto de inflexión en relación al espacio público con la aplicación de las políticas de la década de 1990, señalando la privatización progresiva de los ámbitos públicos, y las pautas de socialización que se encontraban asociadas

\footnotetext{
Menem Carlos Saul, Presidente argentino en el periodo que abarca desde 1989 hasta 1999.
} 
Vol. 1

No. 1

Jul - Dic 2016

ISSN: 2590-9215 (En línea) PP: 50-72 a los mismos. En este sentido el siguiente testimonio del entrevistado es revelador:

Mirá, según la Constitución Nacional desde el río hasta 35 metros de la costa es territorio público, antes estaba bajo dominio de la Prefectura. Pero en la época de Menem vendió todo y fue en contra de la Ley y todo... Así que a partir de esa época todo esto se llenó de clubs, tenés todos esos clubs de mucha plata, está el Boating Club, y todos esos clubs náuticos a los que va la gente de plata de zona norte. San Fernando se llenó de clubs náuticos en donde la gente va como para pertenecer a un grupo de gente, para codearse con su gente. Así que hace 30 años esto era hermoso. Y hace 50 años, ¡hasta te podías bañar! Cuando éramos chicos, salíamos del colegio, veníamos con mis compañeros iy nos metíamos con el agua hasta acá! [Señalándose el pecho]. (Mismo entrevistado)

Ahora bien, retomando el cambio de paradigma, en Victoria se encuentran, aún hoy, huellas del modelo de Industrialización por Sustitución de Importaciones (ISI), donde prevalece como principal elemento estructurante de la morfología urbana los emprendimientos productivos de tipo fabril

de capitales nacionales en alianza con políticas públicas de transporte, vivienda, gestión del suelo y educación. La empresa de capitales nacionales de neumáticos Fate y el barrio obrero homónimo que allí se ubican, son ejemplos paradigmáticos de ese modelo de ciudad, en el que el barrio construyó sus casas y porque no su identidad en función de la fuente de trabajo. Es así que asfaltaron calles, se proveyó de servicios (agua, gas, electricidad), se construyeron escuelas, plazas y se extendieron las vías del Ferrocarril. Cabe mencionar, que el ferrocarril fue el principal articulador de la ciudad desarrollista para permitir su expansión en forma de "mancha de aceite", es decir, sin perder continuidad. Es de esta manera que:
El transporte público cumple la función de articulador horizontal del continuum espacial en el que se combinan residencia de sectores populares, producción y espacios públicos. La vida cotidiana y la vida productiva aparecen relacionadas de manera directa en términos físicos (Ciccolella, 2007, p.28).

Por tal razón, aún luego de las transformaciones en las ciudades latinoamericanas desarrollistas y en particular, de Victoria, permanecen huellas de aquel modelo, huellas resignificadas, o con algunos cambios, elementos novedosos y desaparición de elementos que antes fueron relevantes y la permanencia de algunas formas socio-espaciales propias del modelo anterior. En este sentido, tanto el espacio como las instituciones públicas (principalmente aquellas que han sufrido el proceso de descentralización del Estado nacional) y el ferrocarril se encuentran en un progresivo y profundo deterioro, además de encontrarse parcialmente privatizados.

\section{Discusión.}

\subsection{La ciudad com-fusa.}

El término ciudad com-fusa construido por Abramo emerge de este funcionamiento del mercado del suelo en la producción de las grandes ciudades promoviendo una doble y simultánea estructuración que concilia una forma de ciudad difusa con una forma compacta. La hipótesis que sostiene el autor afirma que siendo el mercado el mecanismo con mayor poder hegemónico, luego de las reformas estructurales, en materia de producción de ciudades y de coordinación en las decisiones del uso de los suelos, quien promovió a lo largo de toda América Latina, la conformación de ciudades con características hibridas, refiriéndose con ello a su morfología en tanto uso del suelo paralelamente con los modelos de ciudades tradicionales modernas. Ciudad moderna que consta de 
dos modelos paradigmático, materialmente hablando, por un lado identifica un modelo de "mediterráneo o continental" donde el diseño de la ciudad aparece como compacto con una utilización del suelo con carácter intensivo, tal es el caso de los barrios populares, lo que también se conoce como construcciones "masivas" (al estilo de los monoblocks) y por el otro lado un modelo "anglosajón" que responde a un concepto de ciudad con una utilización del suelo de carácter extensivo y con un abaja densidad no solo predial sino también residencial, tal es el caso de los barrios cerrados los cuales constan de varias extensiones de tierra las cuales albergan a una baja densidad poblacional, para el caso puntual de Victoria. Ahora bien, estos dos modelos de ciudad, según el autor, son promovidos por el mercado en las ciudades latinoamericanas en forma simultánea queriendo decir con ellos, que la característica primordial de las ciudades de hoy es que su estructura es compacta y difusa al mismo tiempo. Entonces es así como la producción de ciudades se entienden como ciudades com-fusas de acuerdo a la su utilización del suelo compacta y difusa a la vez. (p.37)

\subsection{Heterotopía y Privatopía}

Adentrarse en los discursos sobre la ciudad moderna, el espacio en el que vivimos, el lugar donde se desarrolla la erosión de nuestra vida, de nuestro tiempo y de nuestra historia, es en sí mismo, un espacio heterogéneo en tanto lugares y relaciones sociales en donde las heterotopías conforman el mundo contemporáneo por excelencia. Se entiende por éste concepto, de acuerdo al trabajo de M. Foucault, a los "espacios reales", cuya localización es posible y su existencia se da en todas las sociedades y en todos los tiempos, pero que se hacen presente como "contra-espacios o contra- emplazamientos" nítidamente separados de todos los demás, especie de lugares que están por fuera de todos los lugares, aunque sean sin embargo efectivamente localizables, donde prima una lógica de aislamiento y exclusión que contradice el normal desarrollo de las relaciones humanas cotidianas y en donde la diferenciación se hace manifiesta con todo su potencial subversivo.

Estos contra-espacios, sugerentes entre sí, son aquellos espacios que se construyen con la imaginación sobre la realidad física de un espacio real, dimensionable, adquirible con los sentidos, en definitiva, susceptibles de ser dibujado. Es la capacidad de edificar sobre lo construido, de alterar la significación real de un área a partir de la imaginación, de proyectar en términos emocionales un significado que va muchos más allá que el estrictamente dado por la dimensión física y funcional de la arquitectura.

Una heterotopía tiene el poder de yuxtaponer en un solo lugar real múltiples espacios. Tiene por rol llevar adelante dos procesos, por un lado crear un espacio de ilusión que denuncia como más ilusorio todavía todo el espacio real, todos los emplazamientos en el interior de los cuales la vida humana está compartimentada y por el otro, crear otro espacio real, tan perfecto, tan meticuloso, tan bien ordenado (los barrios cerrados o privados mencionados más arriba), como lo es su opuesto, tan desordenado, mal administrado y embrollado, lo que denominó como "espacios que restan" ( las villas y los asentamientos por sobre todas las cosas). Foucault anuncia que la misma consta siempre de un sistema de cierre que la aísla del espacio que las rodea y otro de apertura.

Se considera que retomar este término es de suma utilidad para pensar Victoria como un lugar en el que se yuxtaponen varios espacios que normalmente serían incompatibles, y con diferentes espacios nos referimos a disimiles configuraciones urbanas o mejor dicho diferentes formas de producción urbana (barrios cerrados, villas, barrios populares por nombrar los más
No. 1

Jul - Dic 2016

ISSN: 2590-9215 (En línea) PP: 50-72 
Vol. 1

No. 1

Jul - Dic 2016

ISSN: 2590-9215 (En línea)

PP: 50-72 usuales en Victoria) contradiciéndose así con la idea foucaultiana acerca de que habitamos dentro de un conjunto de relaciones que definen emplazamientos los cuales se tornan irreductibles y no superponibles entre sí. En palabras de Foucault:

El espacio en el que vivimos (...) es un espacio heterogéneo. En otras palabras, no vivimos en una especie de vacío, dentro del cual localizamos individuos y cosas. (...) vivimos dentro de una red de relaciones que definen emplazamientos que son irreducibles unos a otros y absolutamente imposibles de superponer (Foucault 1967, p. 2).

Cuestionarse sobre este aislamiento nos hace reparar en la existencia de dos fuerzas que son centrales en las dinámicas de las privatizaciones y de la reclusión, por un lado el miedo y por el otro el consumo, las cuales se vinculan para orientar las relaciones sociales, dando como resultado una polarización de la sociedad que conforma un paisaje urbano modificado, más segmentado y desarticulado, bajo la promoción del encierro urbano, en donde en un juego de palabras podemos decir que el encierro es el recurso utilizado hoy para excluir en el espacio y que a su vez la exclusión se hace más evidente por el mismo encierro. Las urbanizaciones cerradas o privadas son entendidas no solo por quienes las habitan sino también por quienes las promocionan como "mundos aparte" que procuran un modo de vida total y de alta calidad, lo que se entiende como una alternativa de vida ante la ciudad desordenada y sus espacios públicos degradados. En relación con esto Teresa Caldeira dice:

Por aislamiento se entiende la separación de aquellos considerados inferiores desde el punto de viste social, y como no se cansan de repetir los constructores y los agentes inmobiliarios, la seguridad es el factor clave para garantizar esto, lo cual significa, vallas y muros alrededor de la urbanización, guardias jurados que vigilen las entradas a todas horas $\mathrm{y}$ un despliegue de instalaciones $\mathrm{y}$ servicios para mantener fuera a los otros. (Caldeira 1996, p. 7)

En este sentido, la inseguridad, pasa a ser una fuerza significativa para demandar y justificar la segregación de espacios y de grupos sociales, para promover el control, la privatización y la clausura de las actividades cotidianas, llevando la vida individual y social hacia los interiores y promoviendo la mirada sobre el espacio público como territorio caótico.

Con el encierro, es precisamente el sentimiento de inseguridad el que se refuerza, por la estrecha relación que guarda con "la incomunicación y con el abandono de los espacios públicos. Este repliegue de los ciudadanos y las ciudadanas hacia lo privado hace que se limite el contacto con las personas del entorno y se pierda el control sobre los espacios. (Naredo, 200. P .4).

El miedo, alimentado por la cantidad alarmante de noticias que difunden los medios de comunicación, tanto presunta como auténtica, es un factor que se ha agudizado y con ello se ha intensificado la reconstrucción de espacios con excesivos sistemas de seguridad tanto así como la propagación de la popularidad de los barrios cercados, privados y seguros. La materialización del mismo en la ciudad ha tomado distintas expresiones donde buena parte de ellas confluye en la privatización del espacio urbano, tal es el caso de la zonas costeras de todo el Partido de San Fernando, además del incremento de la vigilancia en lugares públicos. La finalidad fundamental que subyace a estas configuraciones es la de dividir, excluir y segregar, en lugar de facilitar 
lugares de encuentro, de comunicación y de acercamiento entre los habitantes de los diferentes sectores sociales de la ciudad.

El miedo se materializa en el muro; es físicamente concreto. Pero los muros pueden ser paredes reales o simbólicas que promueven la privacidad, la cohesión y la identidad; que sirven para distanciar a los más pudientes, de los otros, de los que forman parte de la ciudad residual. (R. Chumillas, 2005, pp.127-135).

Esto se puede observar en una entrevista realizada a un señor que vive en Victoria desde hace casi 30 años:

Si evitamos. O sea. Yo personalmente no. ¿Si de pronto tendría que a alguien que no es de acá bueno recomendarle? Bueno cuando cruzas la vía, eso sería una zona para evitar. Después tenés, bueno lamentablemente también la parte ente las vías del tren y el cementerio toda esa zona, porque están las villas pero, a ver no quiero discriminar porque tengo amigos en la villa. Pero están ahí la gente que hace daño o que te joroban la vida son de la villa están ahí. Lamentablemente es así. (Entrevistado, hombre de unos 50 años).

De esta forma el entrevistado nos brinda información acerca de las zonas que encerrarían miedo y que habría que evitar al momento de transitar las calles de Victoria. Miedo que rodea a aquellos barrios cerrados que se instalaron en esos terrenos huyendo del mismo. Los complejos cerrados privados aparecen como las nuevas tendencias urbanas contemporáneas y son la forma de urbanización ofrecida por el mercado para hacerle frente a las problemáticas sociales y a las insuficiencias urbanas mediante la construcción de un espacio colectivo que les es común, donde la existencia de una frontera delimita entre "un nosotros" y "un ellos", un espacio que se presenta como ordenado en contraposición con otro que aparece como salvaje, menospreciando a ese "otro" que no pertenece al mismo círculo, que se va convirtiendo en amenaza, del cual hay que protegerse. Ahora bien, la reclusión deja de ser tal, en tanto que la ubicación espacial de dichos barrios en su gran mayoría se encuentra contorneada por las mismas formas de urbanización de las cuales ellos se quieren apartar, donde habitan los individuos a los que les temen pero que por otro lado les son funcionales para el desempeño de labores en materia de prestación de servicios y mantenimiento de sus espacios.

La privacidad trae consigo la privación del intercambio material y simbólico para con la sociedad toda. Se observa en éste proceso un debilitamiento de los vínculos $\mathrm{y}$ de los procesos de interacción que unen de una manera $\mathrm{u}$ otra al individuo con el colectivo. Los lazos aparecen quebrados. El encerramiento materializa la exclusión social porque los vínculos funcionales, los sociales y los culturales, se han roto ( $\mathrm{R}$. Chumillas, 2005, pp.127-135). Los espacios cerrados favorecen la interrupción de las relaciones sociales, rompen con la continuidad de las mismas, entorpecen la conectividad con las ciudades e impiden tanto el desarrollo de las comunicaciones entre los interlocutores como la certeza de existencia de un par. La paradoja de éstos tiempos globalizados y de apertura, es que cada vez más los individuos se encierran en sí mismos en comunidades que aparecen como simuladas y bajo una serie de muros tanto físicos como simbólicos en una constante búsqueda de bienestar, exclusividad y seguridad, convirtiéndose de éste modo en claustros que forman microcosmos segregados del resto. La privatopía en tanto configuración espacial que apunta a la privatización de los ejes fundamentales que marcan los ritmos, funciones y disposiciones de la vida en la ciudad organizando la morada
No. 1

Jul - Dic 2016

ISSN: 2590-9215 (En línea) PP: 50-72 
Vol. 1

No. 1

Jul - Dic 2016

ISSN: 2590-9215 (En línea)

PP: 50-72 y la vecindad en torno a fraccionamientos amurallados y segregado del dominio público, viene a ofrecerse como remedio a la falta de regulación económica que en el tardo-capitalismo provocó el colapso de lo público, sublimando una vida en comunidad y protegida, estableciendo además límites claramente definidos, donde perímetros acorazados excluyen lo bárbaro, protegiendo lo selecto.

\section{Conclusión.}

A lo largo de todo nuestro análisis se intentó dar cuenta de que tipo de ciudad hablamos cuando hablamos de Victoria, cuáles son sus características particulares y a que se debe que se haya configurado de esa manera y no de otra. Se sostiene además que los conceptos utilizados para describir dicha ciudad no se remiten de manera exclusiva a ella, ya que teniendo en cuenta que los términos utilizados desembocan de fenómenos que son generales, o que por lo menos afectaron a toda Latinoamérica, los mismos pueden ser utilizados para explicar otras ciudades que presenten las mismas características.

Se entiende la localidad de Victoria como un espacio urbano plagado de rupturas, fronteras y discontinuidades que señalan la segregación $\mathrm{y}$ en el caso de los barrios cerrados de auto-segregación, de distintas culturas incompatibles, incapaces de interactuar y encontrarse en un mismo lugar, pero que terminan disponiéndose juntas, ya que las heterotopías por su forma y su función así lo permiten.

La consolidación del capitalismo occidental de manera dominante ha ido estableciendo nuevas formas de interacción y de construcción de comunidades. La conformación de las sociedades de consumo, la masificación de los medios de comunicación y el aumento en la divulgación de crímenes y violencia los cuales generan una sensación de miedo constante e inseguridad han contribuido de manera significativa en la estimulación al control, la privacidad y el apartamiento, lo que entendemos como privatopía. El precio para el acceso a la privacidad es alto, el miedo y la exclusión son gratis.

Expuestas han quedado las transformaciones urbanas radicales a las que ha sido sometida la localidad de Victoria gracias al giro hacia el nuevo paradigma neoliberal que se vino gestando desde los años 70 pero que se profundizó en los años venideros más precisamente en los 90. Las consecuencias de dicho cambio no solo se visualizan con los diferentes estilos de producciones urbanas que allí coexisten sino que se hacen presentes en la tajante fragmentación residencial y segregación social que puede ser observada. Brecha entre ricos y pobres que no se presenta como algo novedoso pero sí que pasa a ser visibilizada y hasta se podría decir que en Victoria, llega a ser naturalizada porque quienes habitan la zona. Brecha que se manifiesta en las ostentosas casas que lindan con barrios populares y humildes, donde queda explicito quieres son los beneficiarios del cambio de paradigma y quienes por otro lado, padecen más el corrimiento del Estado como pieza fundamental a la hora de detener el avance despiadado del mercado.

Finalmente ha quedado planteado en el trabajo de investigación que la ausencia así como también la presencia estatal y su buena voluntad política en materia urbana es central al momento de planificar u ordenar una ciudad. El Estado de la mano de la arquitectura social son los encargados de proveer a sus habitantes ciudades confortables y dignas si hablamos de un tipo ideal de ciudad, pero por otro lado, la ausencia de los mismos da como resultado una ciudad como Victoria, un lugar donde 
prima el caos, el conflicto y la indiferencia por sobre todas las cosas.

\section{Bibliografía.}

Abramo Pedro (2002) La ciudad com fusa: mercado y producción de la estructura urbana en las grandes metrópolis latinoamericanas. Santiago de Chile. EURE VOL 38 Num. 114 mayo 2012.

Antunes, Ricardo (2001), ¿Adiós al trabajo? Ensayo sobre la metamorfosis y la centralidad del mundo del trabajo, Cortez Editora, Brasil.

Bauman Zigmnunt (1997) Tiempos Liquidos. TusQuets Editores. Mexico.

Bauman, Zygmunt (2003), Comunidad, F.C.E., Argentina.

Bettin, Gianfranco (1982). Los sociólogos de la ciudad. Barcelona: Editorial Gustavo Gili, S. A.

Bialakowsky, A. (2011) "Imágenes en la irrupción de la memoria coproducida. Historias de vida de núcleos urbanos segregados y secuestraciones" Ponencia presentada en las IX Jornadas de Sociología, Pre ALAS, Recife Bialakowsky, A. et al (2001) "Fuerte Apache, de la salud de la violencia o de la violencia de la salud en Salud Problema y Debate, Año XI, $\mathrm{N}^{\circ} 23$, Buenos Aires.

Bialakowsky, A.; Zagami, M.; Crudi, R.; Reynals, C; Costa, M. y equipo (2005) Núcleos Urbanos Segregados. Proceso de exclusión-extinción social y prácticas institucionales. Hacia la gestión de un hábitat sostenible, comp.Borthagaray, J.M., Igarzábal de Nisal, M.A. y Wainstein-Krasuk, O. Ed. Nobuko. Facultad de Arquitectuta y Urbanismo. Universidad de Buenos Aires (FADU - UBA). Centro de
Información Metropolitana. Instituto Superior de Urbanismo, Territorio y el Ambiente. Centro de Estudios del Hábitat y la Vivienda (CEHyV), Buenos Aires.

Bialakowsky, Alberto L.; Crudi, Roxana G.; Ferenaz, Juan; Ocampo, María Rosa: Coproducción e Intelecto Colectivo. Investigando para el cambio con la fábrica, el barrio y la Universidad; Alberto L. Bialakowsky (director) Editorial Teseo; Buenos Aires, Argentina; (2013); Capítulo III: "Núcleos Urbanos Segregados: Travesía a una historia co-narrada".

Bourdieu, P. (2010) La miseria del mundo, Fondo de Cultura Económica, Buenos Aires. (2012) Capital cultural, escuela y espacio social, Siglo XXI, Buenos Aires.

Burzaco, E.; Garavano, G. y Gorgal, D. (2004). "Introducción”, “¿Por qué llegamos a estos niveles delictivos?", "La inseguridad en el nuevo paisaje social" y "Plan de intervención inmediata sobre el crimen y la violencia", en Mano Justa. Una reflexión sobre la inseguridad pública y una propuesta para superar la crisis, El Ateneo, Buenos Aires.

Butler, J. (2006) "Prefacio" y "Capítulo 2": "Vida precaria: el poder del duelo y la violencia”, Buenos Aires: Paidós.

Caldeira, T.P.R., (1996). Building up walls: the new pattern of spatial segregation in Sao Paulo, en Manuel Herrera Usagre (2006) Segregacion espacial y comunidades cercadas: La heteropotopia del miedo y la seguridad

Castel, R. (1997) Las metamorfosis de la cuestión social. Una crónica del salariado, Paidós, Buenos Aires. 
Vol. 1

No. 1

Jul - Dic 2016

ISSN: 2590-9215

(En línea)

PP: $50-72$
Castells, Manuel (2000), "El Cuarto Mundo: capitalismo, informacional, pobreza y exclusión social", en La era de la información. Economía, sociedad y cultura. Fin de Milenio, Vol. III, Siglo XXI editores, México.

Ciccolela Pablo (2007), Transformaciones recientes en las metrópolis latinoamericanas en Fernández Caso, M. Victoria y R. Gurevich (coord.) Geografía. Nuevos temas, nuevas preguntas. Un temario para su enseñanza Buenos Aires. Biblos.

Ciccolella, Pablo (1999) Globalización y dualizaciónen la Región Metropolitana de Buenos Aires. Grandes inversiones y reestructuración socioterritorial en los años noventa, Revista EURE, vol. XXV, $\mathrm{N}^{\circ} 26$, pp. 5-27, diciembre, Santiago de Chile

Creswell, J., \& Plano, V. (2007). Designing and conducting Mixed Methods Research. California: Sage Publications, Inc

De Sousa Santos, B. (2003). "Los modos de producción del poder, del derecho y del sentido común" en Crítica de la razón indolente: contra el desperdicio de la experiencia. Volumen I, Capítulo V: "Para un nuevo sentido común: la ciencia, el derecho y la política en la transición paradigmática". Bilbao: Editorial DescléedeBrouwer.

Deleuze, G. (1995) "Post-scriptum sobre las sociedades de control". Conversaciones. Valencia:Pre-textos.

Donadio L, Torrez Jeannette. Las formas de producción del espacio en Victoria. III Encuentro Internacional de Teoría y Práctica Política. Estado, política y transformaciones sociales en América Latina. Universidad Nacional de Mar del Plata. 2013.
Drucker, Susan J. y Gumpert, Gary (1994) The mediated home in a global village, en Communication Research, 4,págs. 422-438.

Echevarría, Andrea (2014) Asentamientos y estrategias de los sectores populares en un territorio heterogéneo. Revista de la Facultad de Ciencias Sociales, UBA, $N^{\circ} 86$, Buenos Aires.

Foucault Michel (1967), De los espacios otros. "Des espaces autres", Conferencia dictada Francia en el Cercle des études architecturals, 14 de marzo de 1967, publicada en Architecture, Mouvement, Continuité, n 5, octubre de 1984.

Guevara C. y Equipo (2011) Proyecto SI. HyC -21 "Trabajo de crítica e investigación socio urbano sobre la zona estación Victoria y aledaños".

Guevara C. y Equipo (2011) Proyecto UBACyT "Investigación sobre los espacios y las formas en que interactúan los distintos sectores socio- urbanos en el área de Victoria (San Fernando) y La Horqueta (San Isidro) en el G.B.A entre 2011-2014"

Harvey, D. (2008) El derecho a la ciudad, en New LeftReview.

HERZER, H.y otros (1994) “Gestión Urbana en ciudades de tamaño medio de América Latina." Habitat-ONU, Nairobi. (pp120).

M. Maldonado, Asael; Z. Contreras, Laura (2011)La interacción social en el pensamiento sociológico de Erving Goffman Espacios Públicos, vol. 14, núm. 31, mayo-agosto, 2011 pp. 158175 Universidad Autónoma del Estado de México Toluca, México. 
Mckencie Evan, (1996), Asociaciones de Propietarios y el Surgimiento del Gobierno Residencial Privado. Estados Unidos. Yale University Press.

Mészáros, István (1999), Más allá del Capital. Hacia una teoría de la transición, Vadell Hnos. Editores, ValenciaCaracas, Venezuela.

Mongin, O. (2006) La condición urbana. Buenos Aires. Ed Paidós.

Murillo, S. (2008). "Empoderar la sociedad civil para reforzar el Estado" en Colonizar el dolor. La interpelación ideológica del Banco Mundial en América Latina. El caso argentino desde Blumberg a Cromañón. Buenos Aires: Clacso. (Capítulo VI).

Naredo Molero, M. (2001) Seguridad urbana y miedo al crimen Polis, Revista de la Universidad Bolivariana, vol. 1, núm. 2, p. 0 Universidad de Los Lagos Santiago, Chile

Oszlak, Oscar (1991) - Merecer la ciudad. Los pobres y el derecho al espacio urbano - Cedes - Humanitas, Buenos Aires.

Plan de desarrollo urbano (2006) Subsecretaría de Planeamiento Urbano Tierras y Vivienda (ex Subsecretario Sr. Gustavo Aguilera). Área de Planeamiento Urbano (Arq. Vera Ponce Betti), MSF (Gestión Osvaldo Amieiro) e Instituto del Conurbano Arq. Eduardo Reese, Arq. Alejandra Akiyama, Arq. Marcela D'Liberis, Arq. Nélida Entesano y Arq. Lilia Freire.

Rodríguez Chumillas, Isabel (2005), «i)Privatopía» versus ciudad pública? La materialización del miedo en el espacio urbano», en Obdulia Gutiérrez (coord.), La ciudad y el miedo, Barcelona, Grupo de Geografía
Urbana de la Asociación de Geógrafos Españoles / Universitat de Girona.

Rodriguez Lastaga Francisco (2006), La estrategia espacial de las heterotopias: ¿El poder organiza espacios de exclusión o de fijaccion? Universidad Santiago de Compostela. España. Revista de Xeografía, Territorio e Medio Ambiente.

Seghezzo, G. (2013): "Emergencia y procedencia de la "violencia policial" como objeto de conocimiento en la Argentina contemporánea", en Modos de producción de conocimiento en las ciencias sociales: la "violencia policial" como objeto de estudio en la Argentina contemporánea, Tesis de Doctorado, Facultad de Ciencias Sociales, Universidad de Buenos Aires.

Soldano, Daniela (2014) El conurbano bonaerense como expansión, desigualdad y promesa.Revista de la Facultad de Ciencias Sociales, UBA, $N^{\circ} 86$, Buenos Aires.

Sotolongo Codina Pedro Luis; Delgado DíazCarlos Jesús, (2006) La revolución contemporánea del Saber y la Complejidad social. CLACSO Libros, Colección

Campus Virtual, Buenos Aires.

Svampa, M. (2001) Los que ganaron. La vida en los countries y barrios privados, Ed. Biblos, Buenos Aires.

Torres, H. (1998) Procesos recientes de fragmentación socio-espacial en Buenos Aires. La suburbanización de las elites, Ponencia presentada en el Seminario El nuevo milenio y lo urbano, Ed. Mimeo, Buenos Aires. 
Vol. 1

No. 1

Jul - Dic 2016 ISSN: $2590-9215$ (En línea)

PP: $50-72$

Wacquant, L. (2000). Las cárceles de la miseria. Buenos Aires. Manantial

Yujnovsky, Oscar (1984) “Claves políticas del problema habitacional argentino 1955/1981" Grupo Editor Latinoamericano Harvey, D. (1998) La condición de la posmodernidad, Buenos Aires, Amorrortu Editores.

Sassen, S. (1999) La ciudad global, Buenos Aires, Eudeba. 